$\overline{\mathrm{AEET}}$

ASOCIACIÓN ESPAÑOLA DE ECOLOGÍA TERRESTRE
Ecosistemas 21(3):123 [Septiembre-Diciembre 2012] Doi.: 10.7818/ECOS.2012.21-3.22

Artículo publicado en Open Access bajo los términos de Creative Commons attribution Non Comercial License.

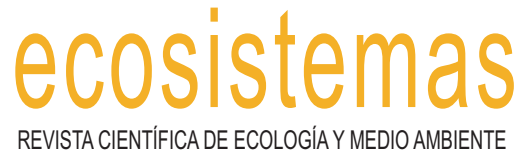

ISSN 1697-2473 / Open access

NOTAS

disponible en www.revistaecosistemas.net

\title{
El estudio sobre la salinidad oceánica de la Barcelona World Race ayuda a analizar el cambio climático
}

\author{
David Jané ${ }^{1, *}$ \\ (1) Solsona Comunicación, Rambla de Catalunya 120, 3º 08008 Barcelona. España.
}

* Correpondencia: D. Jané [djane@solsonacomunicacion.com]

> Recibido el 30 de noviembre de 2012, aceptado el 3 de diciembre de 2012.

Jané, D. (2012). El estudio sobre la salinidad oceánica de la Barcelona World Race ayuda a analizar el cambio climático. Ecosistemas 21(3):123. Doi.: 10.7818/ECOS.210.21-3.22

- Es el análisis continuo más largo de la historia, realizado sin gasto energético y con un coste reducido.

- El origen de los datos es especialmente relevante ya que provienen en buena parte de zonas inexploradas.

- Todas las embarcaciones de la Barcelona World Race 20142015 participarán en la recogida de datos en las mismas zonas para poder comparar y contribuir a predicciones climáticas.

El 7 de junio tuvo lugar la presentación pública del Estudio de la Salinidad Oceánica, en el Centre d'Interpretació de la Barcelona World Race en el Moll de Llevant.

El estudio ha permitido obtener por primera vez y de manera fiable datos relevantes sobre la salinidad en zonas muy poco exploradas, especialmente en los océanos del sur. Las informaciones están sirviendo para confirmar y ajustar la que está captando el satélite Soil Moisture and Ocean Salinity (SMOS), lanzado por la Agencia Europea del Espacio el año 2009, según ha explicado el investigador del Institut de Ciències del Mar y del CSIC, Jordi Salat.

También ha remarcado que "es el análisis continuo más largo de la historia, ya que se han recopilado de media más de 3 datos por hora, que equivale a 1 cada 3 millas, y por primera vez, en los $360^{\circ}$ del planeta y en latitudes extremas". Ha añadido que "se ha hecho sin gastos de energía, ni contaminación y con coste mínimo". $\mathrm{Ha}$ apostillado que "es un proyecto pionero y ya ha recibido 2 premios": una de las 50 banderas conmemorativas del 50 aniversario de la Comisión Oceanográfica Intergubernamental (COI) de la UNESCO por la recogida de datos de interés oceanográfico mediante una competición deportiva; y el premio al mejor poster que otorgó el $44^{\circ}$ Coloquio sobre Dinámica Oceánica de Lieja, uno de los congresos más consolidados y con más prestigio, por el uso de los datos obtenidos para validar los del satélite SMOS

Otra novedad es que en la próxima Barcelona World Race (2014-2015) las 14 embarcaciones participantes en esta regata de circunnavegación oceánica sin escalas tendrán un dispositivo para continuar el estudio. Se cuenta con "el compromiso de realizar el mismo proyecto en las mismas zonas, lo que permitirá comparar y analizar si hay cambios en la salinidad y su posible implicación en estudios de cambio climático". Además servirá según ha avanzado Maite Fandos, "para controlar el nivel de contaminación marina y la presencia de microplásticos". En este sentido Fandos ha destacado que la Barcelona World Race es "una referencia deportiva y científica y demuestra el compromiso de la FNOB con el medio ambiente".

El meteorólogo Tomàs Molina ha remarcado que "los datos recopilados serán útiles para saber cómo es el mundo ahora y poder prever cómo será el futuro". Gracias a este análisis se podrán estudiar aspectos de la dinámica marina global, conocer mejor el ciclo hidrológico y ajustar modelos climáticos.

La navegante Anna Corbella ha explicado que superado "el ecuador, en medio del Atlántico, estaba lleno de plásticos y materiales de pesca envejecidos que incluso crean las llamadas 'mareas de plásticos'". También ha hecho un Ilamamiento a evitar la contaminación acústica que hay en el mar y que afecta a los cetáceos.

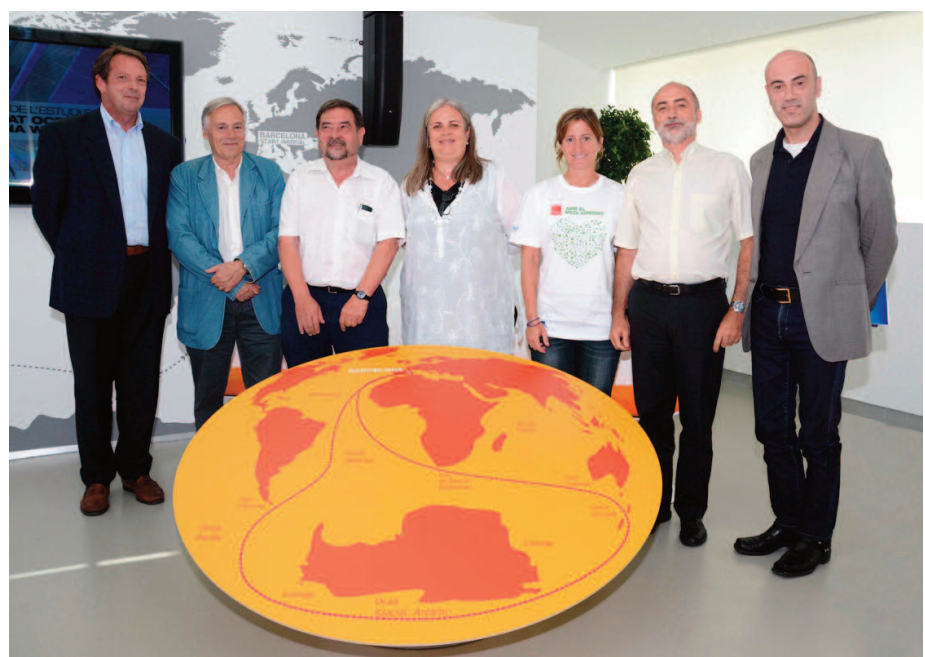

Fig.1. Fotografía tomada en la Presentación. De izquierda a derecha: Andor Serra, director general de la FNOB; Jordi Serra, profesor de Geología de la UB, y miembro del Consell General del Consorci El Far; Jordi Salat, investigador del Institut de Ciències del Mar; Maite Fandos, teniente de alcalde de Calidad de Vida, Igualdad y Deportes; Anna Corbella, Skipper y embajadora medioambiente de la Barcelona World Race; Albert Palanques, director del Institut de Ciències del Mar y Tomàs Molina, periodista y Jefe de Meteorología de Televisió de Catalunya. @ Mireia Perelló / FNOB. 